\title{
NMR Spectroscopy as a Tool for Studying Asphaltene Composition
}

\author{
Jelena Parlov Vuković, ${ }^{1, *}$ Predrag Novak, ${ }^{2}$ Tomislav Jednačak ${ }^{2}$
}

\footnotetext{
1 INA-Industrija nafte d.d., Refining \& marketing business division, Central testing laboratory, Lovinčićeva 4, HR-10002 Zagreb, Croatia

2 University of Zagreb, Faculty of Science, Department of Chemistry, Horvatovac 102a, HR-10000, Zagreb, Croatia

* Corresponding author's e-mail address: jelena.parlov-vukovic@ina.hr
}

RECEIVED: June 21, 2019 * REVISED: October 8, 2019 * ACCEPTED: October 8, 2019

\begin{abstract}
Asphaltenes are the most polar oil components with molecular weights between 500 and 1000 Da, which primarily consist of carbons and hydrogens, some heteroatoms, such as nitrogen, sulphur, oxygen and traces of nickel, vanadium and iron. Owing to their extreme complexity, it is almost impossible to completely identify all the compounds present in asphaltene samples. Various analytical techniques and approaches were used to characterize asphaltenes but their structure and composition are still a matter of thorough investigations. NMR spectroscopy can reveal useful information on asphaltene molecular architecture and aggregation process. In that respect, one- and twodimensional NMR techniques have widely been employed. Although NMR spectra of these complex mixtures are difficult to interpret, they still can provide valuable data, especially in combination with statistical methods. Some distinctive examples of using NMR spectroscopy to study asphaltenes are given in this review.
\end{abstract}

Keywords: asphaltenes, composition, structure, properties, aggregation, NMR spectroscopy.

\section{INTRODUCTION}

A common feature of crude oil and its fractions is a very complex chemical composition. Individual crude oil components mainly consist of carbon and hydrogen atoms and have various sizes and structures. However, exact molecular composition of crude oil components is still a matter of thorough studies. Detailed understanding of the crude oil composition and its chemical and physical properties is crucial for the right application of appropriate processing facilities and the quality evaluation of crude oil and its final products. ${ }^{[1,2]}$ The supplies of lighter, conventional crude oils have decreased and one of the important goals of oil industry is to transform large quantities of unconventional, heavy and extra heavy crude oils into high-quality commercial products. Asphaltenes are the most problematic crude oil components and critical to all aspects of petroleum use, including production, transportation and refining. ${ }^{[3]}$ At high temperatures, they can polymerize and convert into coke or asphaltic residue. They may aggregate and precipitate during petroleum processing and form aggregates, causing serious problems including reduction in oil flow, blocking of production pipes and some drawbacks during the processing of heavy ends, such as coke formation, corrosion, catalyst deactivation and poisoning. That can also cause huge production losses. During the past few decades, a great attention has been paid to resolve asphaltene structure and aggregation process.

\section{METHODS FOR ASPHALTENE ANALYSIS}

Many instrumental analytical techniques were used to investigate asphaltene composition, structure and aggregation properties, such as X-ray diffraction (XRD), ${ }^{[2-4]}$ mass spectrometry (MS), ${ }^{[5-9]}$ gas chromatography (GC), ${ }^{[10]}$ fluorescence depolarization (FD), ${ }^{[11]}$ scanning electron microscopy (SEM), ${ }^{[12,13]}$ transmission electron microscopy (TEM), ${ }^{[12]}$ Fourier-transform infrared spectroscopy (FTIR), ${ }^{[14,15]}$ vapor pressure osmometry (VPO), ${ }^{116]}$ smallangle X-ray scattering (SAXS), ${ }^{[17,18]}$ small-angle neutron scattering (SANS), ${ }^{[19-21]}$ nuclear magnetic resonance (NMR) ${ }^{[22-25]}$

(cc) Br This work is licensed under a Creative Commons Attribution 4.0 International License. 


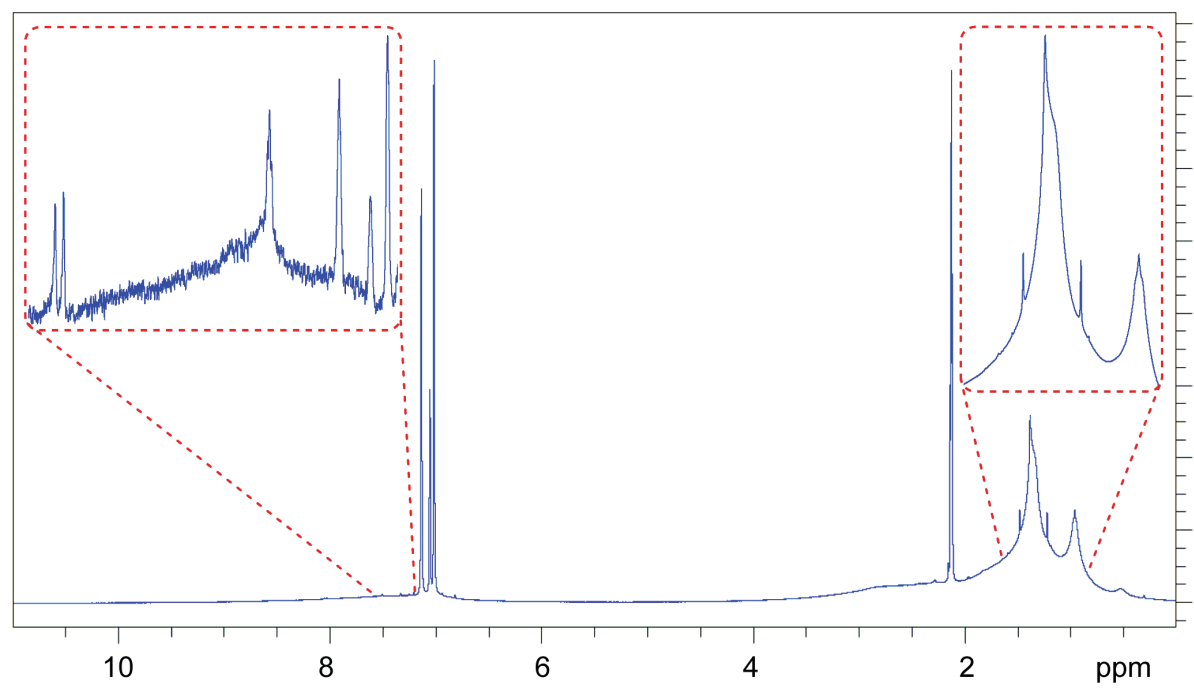

Figure 1. Typical ${ }^{1} \mathrm{H}$ NMR spectrum of asphaltene sample.

spectroscopy and others. Despite of all efforts made to understand asphaltene behavior and structural architecture, there are many details still to be resolved. ${ }^{[26]}$ Analysis of data obtained so far using different methods showed no general agreement on their structure and chemistry. However, those approaches enabled better understanding of and gave insights into asphaltene properties.

\section{MODELS OF ASPHALTENE AGGREGATION}

Over the past few decades, asphaltene chemistry has become one of the most explored fields in the oil research. As previously mentioned, asphaltenes are very complex organic macromolecules consisting of a large number of components with different chemical and physical properties. They contain condensed aromatic and saturated rings, aliphatic moieties, and some heteroatoms, including nitrogen, oxygen and sulfur. They also contain traces of metals, such as nickel, vanadium and iron. The main heteroatom functional groups are thiophene, sulfidic, sulfoxide, pyrolic, pyridine, quinoline, hydroxyl and carboxyl. ${ }^{[27]}$ Asphaltene can contain metal porphyrins and acid-base pairs, oxygen- and nitrogen- functional groups, with negative and positive charges. Historically, exact asphaltene structure has been the matter of a wide debate. As a consequence of that, several models of the asphaltene structure have been proposed. ${ }^{[28-30]}$ However, the most frequently elaborated are two of them: the continental (also called the island or Yen-Mullins) model and the archipelago model. According to the continental model, asphaltenes form a condensed aromatic core of 7-10 rings with substituted alkyl chains while in the archipelago model several aromatic cores are interconnected by alkyl chains and thioether bridges. Asphaltene aggregation is a very complex process that highly depends on the asphaltene origin, physico-chemical environment and refining conditions. Self-association proposed by the island model occurs mostly by $\pi-\pi$ stacking interactions between polyaromatic planes. On the other hand, the archipelago model explains aggregation as the result of bridging and $\mathrm{H}$ bonding interactions. ${ }^{[3,31]}$ In general, the number of asphaltene molecules per aggregate is limited by the molecular structure.

\section{THE ROLE OF NMR SPECTROSCOPY IN ASPHALTENE STRUCTURE DETERMINATION AND AGGREGATION}

\section{One-dimensional Techniques}

A number of research groups investigated the structure and behavior of asphaltenes by using one- and two-dimensional NMR techniques. NMR spectroscopy is one of the most powerful techniques for structure elucidation. It has widely been used to study petroleum and asphaltene chemistry for more than 60 years. ${ }^{[22-25,32-34]}$ Molina et al. demonstrated that the asphaltene samples isolated from various crude oils at the Colorado oil field had considerably different molecular structures, despite the same geological formation. In that study, asphaltene samples were characterized by ${ }^{1} \mathrm{H}$ and ${ }^{13} \mathrm{C}$ NMR spectroscopy. ${ }^{[35]}$ The authors used an inverse gated decoupling and composite pulse decoupling (CPD) sequences to suppress the nuclear Overhauser effect and obtain quantitative spectra. Typical ${ }^{1} \mathrm{H}$ NMR spectrum of asphaltene sample is displayed in Figure 1. 


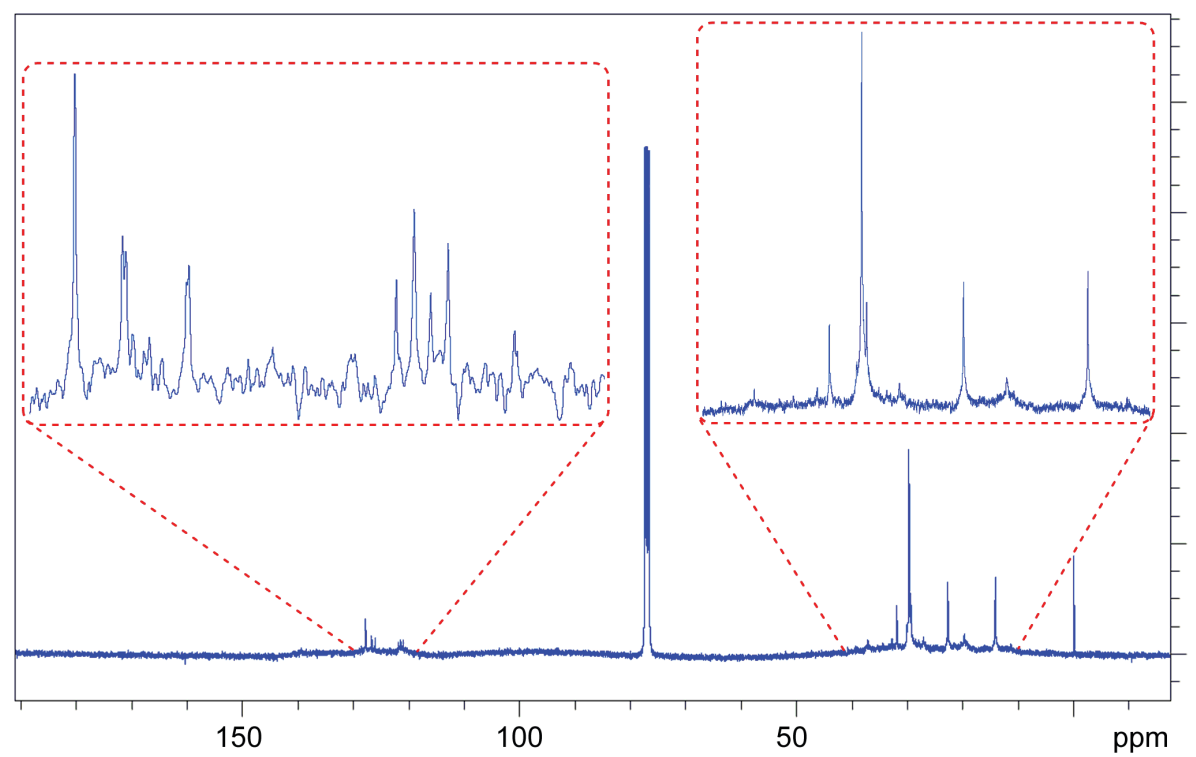

Figure 2. Typical ${ }^{13} \mathrm{C}$ NMR spectrum of asphaltene sample.

Owing to the complexity of asphaltene composition, ${ }^{1} \mathrm{H}$ NMR spectra consist of a number of overlapping signals assigned to different hydrocarbon types. Comprehensive studies of asphaltenes by NMR over the past several decades have revealed characteristic functional groups of the asphaltene compounds and the spectral regions in which their protons resonate which are listed in Table 1.

Furthermore, the signal intensities in quantitative ${ }^{13} \mathrm{C}$ NMR spectra can provide an insight into the aromatic and saturated carbon content in asphaltene samples. Aromatic carbons exhibit ${ }^{13} \mathrm{C}$ NMR signals in the spectral region between 100 and $160 \mathrm{ppm}$, while the signals of saturated carbons are found in the region 0-70 ppm. Typical ${ }^{13} \mathrm{C}$ NMR spectrum of an asphaltene sample is displayed in Figure 2.

The characteristic spectral regions and corresponding functional groups of the asphaltene samples are shown in Table 2.

In addition, the content of unsubstituted $\mathrm{CH}(\mathrm{CH}, \mathrm{ar})$ and quaternary carbons $(\mathrm{Cq}, \mathrm{ar})$ present in the aromatic region can be calculated from the aromatic ${ }^{13} \mathrm{C}$ spectral

Table 1. ${ }^{1} \mathrm{H}$ NMR chemical shift regions for asphaltene samples.

\begin{tabular}{lc}
\hline Functional group & $\begin{array}{c}\text { Chemical shift } \\
\delta / \mathrm{ppm}\end{array}$ \\
\hline Aromatic hydrogens (Har) & $7.20-9.00$ \\
Hydrogens $\alpha$ to aromatic ring $(\mathrm{H} \alpha)$ & $2.10-3.80$ \\
$\beta, \gamma-\mathrm{CH}_{2}$ and $\mathrm{CH}$ in to aromatic ring and & $1.00-2.10$ \\
paraffinic $\mathrm{CH}, \mathrm{CH}_{2}\left(\mathrm{H}_{\beta}\right)$ & \\
$\beta, \gamma-\mathrm{CH}_{3}$ to aromatic ring and paraffinic $\mathrm{CH}_{3}(\mathrm{H} \gamma)$ & $0.50-1.00$
\end{tabular}

region, using the spin-echo ${ }^{13} \mathrm{C}$ experiment. ${ }^{[29]}$ The content of $\mathrm{CH}_{3}, \mathrm{CH}_{2}, \mathrm{CH}$ and quaternary carbon ( $\mathrm{Cq}$ ) in the aliphatic components can be determined from saturated part of the ${ }^{13} \mathrm{C}$ spin echo and ${ }^{13} \mathrm{C}$ APT NMR spectra. From the spectral data it is possible to calculate the substitution and condensation indices. Substitution index represents the ratio between the substituted and substitutable aromatic carbons, while condensation index represents the average number of condensed aromatic rings. In order to better understand the nature of structural changes of asphaltene molecules during thermal cracking of vacuum residues, ${ }^{1} \mathrm{H}$ and ${ }^{13} \mathrm{C}$ NMR spectroscopy was used. ${ }^{[36]}$ The NMR analysis revealed a number of valuable findings and confirmed that the observed reduction in the average molecular weight in asphaltene molecule is mainly due to cracking of the saturated parts of the molecules. It was also observed that the cracking severity increased with the growth of aromatic

Table 2. ${ }^{13} \mathrm{C}$ NMR chemical shift regions for asphaltene samples.

\begin{tabular}{lc}
\hline Functional group & $\begin{array}{c}\text { Chemical shift } \\
\delta / p p m\end{array}$ \\
\hline Saturated carbons (Cal) & $0.00-70.00$ \\
Aromatic carbons (Car) & $100.00-160.00$ \\
Naphtenic carbons (Cn) & Hump in region 60-24 \\
Paraffinic carbons (Cp) & Csat - Cn \\
Normal paraffins (Cnp) & Cpn - Cpn + Cpn $\beta+$ Cpny + Cpn $\delta$ \\
Iso paraffins (Cip) & $160-130$ \\
Quaternary aromatic (Cq,ar) & \\
\hline
\end{tabular}


carbon and carbon bearing hydrogen content. ${ }^{13} \mathrm{C}$ NMR spectroscopy in combination with distortionless enhancement by polarization transfer (DEPT) sequence was employed to study the structure of the asphaltenes. ${ }^{[37]}$ DEPT135 NMR experiment was applied to assess the amount of protonated aromatic carbon, which enabled the determination of aromaticity. ${ }^{[38]}$ In an earlier paper, authors reported the use of DEPT-45 experiment to determine the relative amount of non-protonated and protonated carbon in the aromatic spectral region. ${ }^{[39]}$ The authors showed that interior bridgehead carbon was an important component of asphaltenes, whose identification enabled proper determination of the number of fused rings. Further analysis of ${ }^{13} \mathrm{C}$ NMR data indicated that the molecular sizes in coal-derived asphaltenes were smaller than in virgin petroleum asphaltenes. Since ${ }^{13} \mathrm{C}$ SPE (single pulse excitation) spectra suffered from almost complete overlap of carbon signals between 108 and 129.5 ppm, they carried out the DEPT-45 experiments. Majumdar's research group used HSQC NMR experiment to better resolve overlapping signals in one-dimensional NMR spectra. ${ }^{[0]}$ In this study, the authors investigated various structural parameters of asphaltene-like size of aromatic clusters, number of substitutions per cluster and average aliphatic chain length. The results showed that each polyaromatic cluster consisted of 6-7 aromatic rings, which was in a good agreement with the predicted Yen-Mullins model. Furthermore, the size of the asphaltene nanoaggregate clusters was estimated from the measurement of proton $\mathrm{T}_{1}$ and $T_{2}$ relaxation times. The average molecular weight of asphaltene was calculated to be approximately $720 \mathrm{~g} / \mathrm{mol}$. Avid et al. also employed ${ }^{1} \mathrm{H},{ }^{13} \mathrm{C}$ and DEPT NMR experiments to characterize the asphaltenes isolated from vacuum residues using the toulene-heptane mixtures. ${ }^{[41]}$ The major goal of this work was to study the conversion of asphaltene subfractions separated from Brazilian vacuum residue to coke under normal processing conditions.

\section{Diffusion-Ordered NMR Spectroscopy (DOSY)}

DOSY is a pseudo two-dimensional NMR experiment where proton chemical shifts represent one dimension while translation diffusion coefficients $(D)$ represent the second one. DOSY enables the separation of different compounds according to their diffusion coefficients. Diffusion coefficient is a measure of the translational diffusion behavior of the molecules or aggregates. It strongly depends upon the shape and size of the species, intensity of intermolecular interactions and solution temperature. According to the StokesEinstein equation, diffusion coefficient is described as:

$$
D=\frac{k_{\mathrm{B}} T}{6 \pi \eta R_{\mathrm{H}}}
$$

where $R_{\mathrm{H}}$ is the hydrodynamic radius, $k_{\mathrm{B}}$ is the Boltzmann constant, $T$ is the temperature and $\eta$ is the viscosity of a solution. Assuming that asphaltene molecules are spherical, the diffusion coefficients can be used to determine the hydrodynamic radius of asphaltenes and their aggregates by using the equation (1). Since the spherical asphaltene compounds are bigger than solvent molecules, it is important to take the additional function $f_{\mathrm{s}}$ into account. Owing to the fact that a crude oil sample can contain thousands of components with various shapes, it is not easy to determine the function $f_{\mathrm{s}}$. Hence, it was a common practice to assume the molecule as a sphere, meaning that $f_{\mathrm{s}}$ was equal to 1 . Therefore, the StokesEinstein equation could be written as

$$
D=\frac{k_{\mathrm{B}} T}{c\left(R_{\mathrm{solv}}, R_{\mathrm{H}}\right) f_{\mathrm{s}}(a, b) \pi \eta R_{\mathrm{H}}}
$$

Valuable information about asphaltene samples could also be obtained from the estimated molecular weights of the studied samples. There are several models which could be used for that purpose. An approximate, but general model which relates the diffusion coefficient to the molecular weight for a wide range of molecules in various solvents was proposed by Evans et al. ${ }^{[42]}$ and is based on the equation (3):

$$
D=\frac{k_{\mathrm{B}} T\left(\frac{3 \alpha}{2}+\frac{1}{1+\alpha}\right)}{6 \pi \eta \sqrt[3]{\frac{3 M_{\mathrm{w}}}{4 \pi \rho_{\mathrm{eff}} N_{\mathrm{A}}}}}, \alpha=\sqrt[3]{\frac{M_{\mathrm{ws}}}{M_{\mathrm{w}}}}
$$

$M_{w}$ and $M_{w s}$ represent solute and solvent molecular masses, $\rho_{\text {eff }}$ the effective density and $\alpha$ is the ratio of the radius of the solute to that of the solvent.

Typical DOSY spectrum of asphaltene sample is shown in Figure 3.

Durand et al. applied ${ }^{1} \mathrm{H}$ DOSY NMR technique to obtain a detailed insight into the asphaltene structure and composition. [39] Subsequently, a number of research groups used DOSY NMR spectroscopy to investigate the structure, average size and self-association of the asphaltene aggregates. ${ }^{[1,24-26,29,43-48]}$

A group of authors applied ${ }^{1} \mathrm{H},{ }^{13} \mathrm{C}$ and ${ }^{1} \mathrm{H}$ DOSY NMR experiments to study the relationship between the structural type (continental or archipelago) and aggregation properties of three different asphaltenes. The obtained results pointed towards the presence of predominantly continental structural type and confirmed the formation of nano-, micro- and macroaggregates, according to different diffusion coefficients. ${ }^{[1]}$ DOSY technique was also used to study asphaltenes from various sources. ${ }^{[29]}$ The samples showed different behavior, depending on their chemical composition. It was observed 


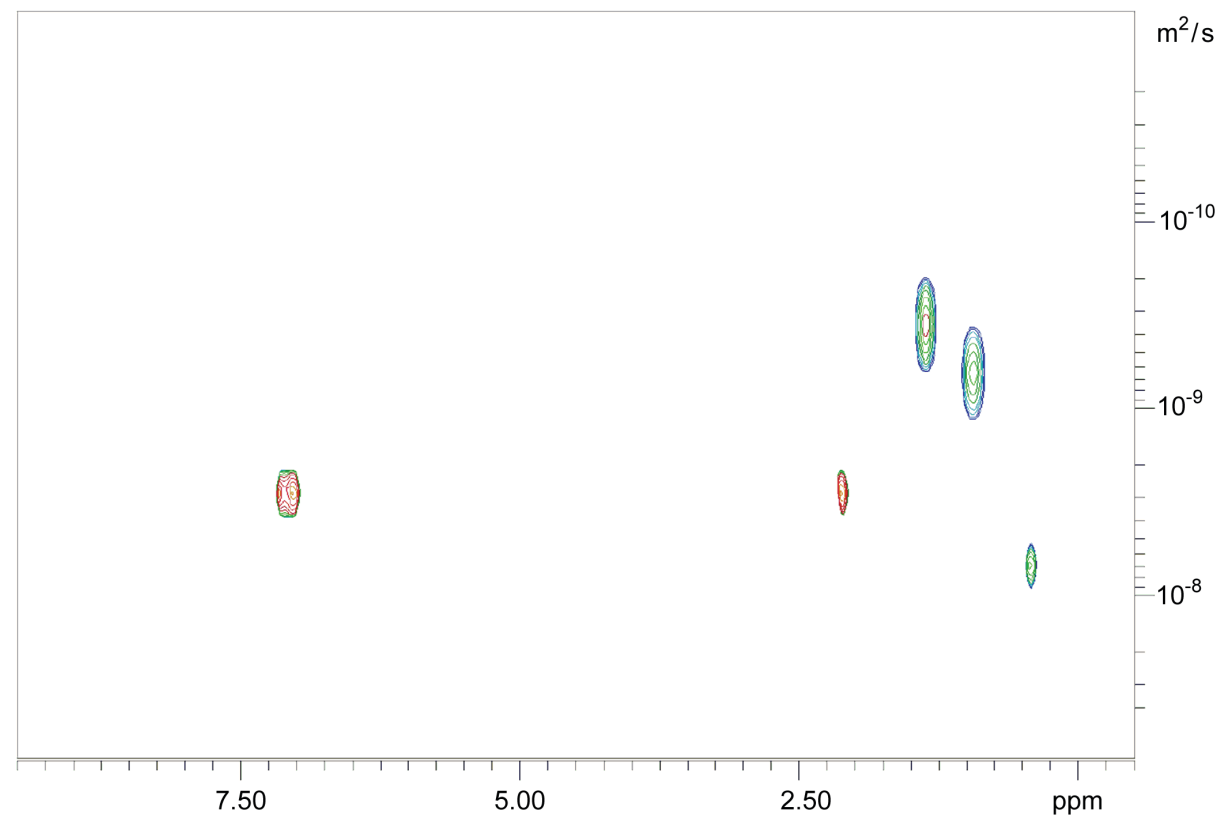

Figure 3. Typical ${ }^{1 H}$ NMR DOSY spectrum of asphaltene sample.

that the aggregation occurred in two steps, yielding two different aggregate classes: nano- and macroaggregates. ${ }^{[13,29]}$ The authors concluded that DOSY was a suitable tool for the asphaltene structure analysis, since the same spectrum could provide both physical and chemical information on the analyte. In order to elucidate the aggregation mechanism of asphaltene, Kawashima at a ${ }^{[46]}$ were investigating the effect of asphaltene concentration on the aggregate size using pulsed field gradient spin-echo ${ }^{1} \mathrm{H}$ NMR. They observed the existence of two types of species. At the concentration range between $0.1-1 \mathrm{~g} / \mathrm{L}$, small- to mediumsized aggregates were observed, while at the concentration range between 10 and $30 \mathrm{~g} / \mathrm{L}$ only aggregates with medium size were detected. ${ }^{[49]}$ Lisitza et al. used DOSY and ${ }^{1} \mathrm{H}$ NMR techniques to explore the molecular dynamics of the initial state of asphaltene aggregation. ${ }^{[50]}$ They studied asphaltenes at low concentrations between 0.05 and $2.1 \mathrm{~g} / \mathrm{L}$ in toluene and determined the onset of aggregation at $0.2 \mathrm{~g} / \mathrm{L}$. From NMR diffusion data, they estimated 20 to 27 molecules per aggregate. Some fluorescence studies ${ }^{[30]}$ implied that asphaltenes may aggregate in non-monotonic fashion into smaller oligomeric species even at lower concentrations forming primary aggregates described as multifluorophore supramolecular complexes with archipelago structures consisting of 10-12 asphaltene molecules each with 1 to 3 aromatic rings. Recently, we have demonstrated[26] that for the accurate determination of diffusion coefficients it is necessary to use convection compensated DOSY pulse sequences to suppress the effects of a thermal convection ${ }^{[49]}$ which occurred in toluene solution of asphaltene aggregates. This is very important for better estimation of molecular weight and hydrodynamic radius of asphaltene species, e.g. monomers and aggregates. Furthermore, our experiments performed at different magnetic fields showed for the first time that diffusion coefficients of aggregates were dependent on the magnetic field strength.[26] A significant increase in diffusion coefficients was observed upon increase in the magnetic field. It was not completely clear what was the cause of such an effect but we demonstrated that it could not be due to relaxation or viscosity effects but rather an intrinsic property of aggregates at different magnetic fields. In our previous paper, we used a combination of DOSY NMR and statistical multi-way methods to investigate the petroleum samples and asphaltenes of different origin. ${ }^{[25]}$ The multi-way TUCKER3 decomposition ${ }^{[51]}$ was used for the first time to analyze two-dimensional matrix of complex NMR data for petroleum samples. DOSY NMR spectra were recorded and analyzed by a multi-way approach and a statistical model was developed in order to pinpoint and separate the asphaltene samples by their origin. Multi-way analysis was performed by using code moonee developed in-house. ${ }^{[52]}$ The proposed model showed that asphaltenes clustered into the same group, irrespective of their geographical origin, indicating similarities in their structure and size. A principal component regression model was also used for quantitative prediction of asphaltenes in vacuum gas oils and vacuum residues from the integrated proton NMR spectra. ${ }^{[24]}$

Some theoretical methods pointed towards the island model as a reasonable average model to explain formation of asphaltene nanoaggregates, while archipelago structures 
were found not to aggregate significantly. ${ }^{[53]}$ Other molecular dynamic calculations of asphaltene aggregation ${ }^{[54]}$ have shown that asphaltene molecules tend to aggregate in a continuous manner with no evidence for distinct formation of nanoaggregates, which was in contradiction to NMR experimental data. However, one should bear in mind that computational methods suffered from the initial predictions of the most appropriate asphaltene structures selected for calculations. ${ }^{[54-56]}$ Nevertheless, those calculations might help in better understanding of the extremely complex asphaltene structure and aggregation phenomena. Further experiments are needed in the future to obtain more reliable data in order to completely resolve asphaltene composition and explain their chemistry.

\section{CONCLUSION}

Over the past few decades, the field of asphaltene science has become frequently explored and there is no single analytical technique that can provide detailed characterization of structure and properties of asphaltene molecules and their aggregates.

We have demonstrated here that NMR spectroscopy is a valuable tool for investigating asphaltene structure, size and aggregation process. Although NMR spectra of asphaltene samples are complex and consist of many overlapping signals, they still provide a wealth of information, especially in combination with statistical methods. With the availability of new NMR techniques, the role of NMR in asphaltene characterization will become even more significant in the future.

\section{REFERENCES}

[1] E. C. da Silva Oliveria, A. C. Neto, V. L. Yunior, E. V. R. de Castro, S. M. C. de Menezes, Fuel 2014, 117, 146151. https://doi.org/10.1016/j.fuel.2013.09.022

[2] S. L. Silva, A. M. S. Silva, J. C. Ribeiro, F. G. Martins, F. A. D. Silva, C. M. Silva, Anal. Chim. Acta 2011, 707, 18-37.

https://doi.org/10.1016/j.aca.2011.09.010

[3] O. C. Mullins, Energy Fuels 2010, 24, 2179-2207. https://doi.org/10.1021/ef900975e

[4] R. Tanka, E. Sato, J. E. Hunt, R. E. Winans, S. Sato, T. Takanohashy, Energy Fuels 2004, 18, 1118-1125. https://doi.org/10.1021/ef034082z

[5] T. F. Yen J. G. Erdman, S. S. Pollack, Anal. Chem. 1961, 33, 1587-1594. https://doi.org/10.1021/ac60179a039

[6] S. I. Anderson, J. O. Jensen, J.G. Speight, Energy Fuels 2005, 19, 2371-2377. https://doi.org/10.1021/ef050039v
[7] G. C. Klein, S. Kin, R. P. Rodgers, A. G. Marshall, A. Yen, S. Asomaning, Energy Fuels 2006, 20, 19651972. https://doi.org/10.1021/ef0600199

[8] A. A. Herod, K. D. Bartle, R. Kandiyoti, Energy Fuels 2007, 21, 2176-2203. https://doi.org/10.1021/ef060642t

[9] K. Qion, K. E. Edwards, M. Siskin, W. N. Olmstead, A. S. Meunnito, G. J. Dechert, N. E. Hoosain, Energy Fuels 2007, 21, 1042-1047. https://doi.org/10.1021/ef060360t

[10] M. Nail, F. Corona, L. Montanari, Rapid Commun. Mass. Spectrom. 1993, 7, 684-687.

https://doi.org/10.1002/rcm.1290070728

[11] H. Groenzin, O. C. Mullins, Energy Fuels 2000, 14, 677-684.

https://doi.org/10.1021/ef990225z

[12] F. Trejo, J. Ancheyta, M. S. Rana, Energy Fuels 2009, 23, 429-439. https://doi.org/10.1021/ef8005405

[13] E. Durand, M. Clemancey, J.-H. Lancelin, J. Verstraete, D. Espinato, A.-A. Quoineaud Energy Fuels 2010, 24, 1051-1062. https://doi.org/10.1021/ef900599v

[14] B. K. Wilt, T. Welch, J. G. Rankin, Energy Fuels 1998 , 12, 1008-1012. https://doi.org/10.1021/ef980078p

[15] B. J. Riley, C. Lennard, S. Fullr, V. Spikmans, Forensic Sci. Int. 2016, 266, 555-564.

https://doi.org/10.1016/j.forsciint.2016.07.018

[16] A. Matsumara, S. Sato J. Japan Inst. Energy 2009, 88, 684-686. https://doi.org/10.3775/jie.88.684

[17] P. M. Spiecker, K. L. Gawrys, P. K. Kilpatrick, J. Colloid Interface Sci. 2003, 26,7 178-193. https://doi.org/10.1016/S0021-9797(03)00641-6

[18] F. Trejo, J. Ancheyta, T. J. Morgan, A. A. Herod, R. Kandiyoti, Energy Fuels 2007, 21, 2121-2128. https://doi.org/10.1021/ef060621z

[19] D. A. Storm, E. Y. Shen, M. M. Deter, Fuel 1993, 72, 977-981. https://doi.org/10.1016/0016-2361(93)90295-D

[20] E. Y. Sheu, J. Phys: Condens. Matter 2006, 18, S2485S2498.

https://doi.org/10.1088/0953-8984/18/36/S19

[21] V. J. Verruto, P. K. Kilpatrick, Energy Fuels 2007, 21, 1217-1225.

https://doi.org/10.1021/ef060456n

[22] J. Jestin, L. Barrie, J. Disper. Sci. Technol 2004, 25, 341-347. https://doi.org/10.1081/DIS-120037682

[23] P. R. Seidl, E. C. A. N. Chrisman, C. C. V. Carvalho, K. Z. Leal, S. M. C. de Menezes, J. Disper. Sci. Technol. 2004, 25, 349-353.

https://doi.org/10.1081/DIS-120037689

[24] J. Parlov Vuković, P. Novak, J. Plavec, M. Friedrich, Lj. Marinić Pajc, T. Hrenar, Croat. Chem. Acta 2015, 88, 89-95. https://doi.org/10.5562/cca2612 
[25] J. Parlov Vuković, T. Hrenar, P. Novak, M. Friedrich, J. Plavec, Energy Fuels 2017, 31, 8095-8101. https://doi.org/10.1021/acs.energyfuels.7b01358

[26] J. Parlov Vuković, P. Novak, T. Jednačak, M. Kveštak, D. Kovačević, V. Smrečki, I. Mikulandra, M. Djetelić Ibrahimpašić, S. Glanzer, K. Zangger, J. Dispers. Sci. Technol. 2019, 1-9. https://doi.org/10.1080/01932691.2018.1561302

[27] J. J. Adams, Energy Fuels 2014, 28, 2831-2856. https://doi.org/10.1021/ef500282p

[28] O. C. Mullins, H. Sabbah, J. Eyssautier, A. E. Pomerantz, L. Barr, A. Ballard Andrews, Y. RuizMorales, F. Mostowfi, R. McFarlane, L. Goual, Energy Fuels 2012, 26, 3986-4003. https://doi.org/10.1021/ef300185p

[29] E. Durand, M. Clemancey, J.-M. Lancelin, J. Verstraete, D. Espinat, A.-A. Quoineaud, J. Phys. Chem. C 2009, 113, 16266-16276. https://doi.org/10.1021/jp901954b

[30] I. N. Evdokimov, A. A. Fesan, A. P. Losev, Energy Fuels 2016, 30, 4494-4503.

https://doi.org/10.1021/acs.energyfuels.6b00027

[31] J. Murgich, J. A. Abanero, O. P. Strausz, Energy Fuels 1999, 13, 278-286. https://doi.org/10.1021/ef980228w

[32] J. Parlov Vuković, S. Telen, V. Srića, P. Novak, Croat. Chem. Acta 2011, 84, 537-541. https://doi.org/10.5562/cca1874

[33] J. Parlov Vuković, V. Srića, P. Novak, Acta Chim. Slov. 2015, 62, 233-240.

[34] J. Parlov Vuković, V. Srića, P. Novak, Kem. Ind. 2012, 61, 513-522.

[35] V. Daniel Molina, E. Ariza, J. C. Poveda, Energy Fuels 2017, 31, 133-139. https://doi.org/10.1021/acs.energyfuels.6b01887

[36] F. S. Al Humaidan, A. Hauser, M. S. Rana, H. M. S. Lababidi, Energy Fuels 2017, 31, 3812-3820. https://doi.org/10.1021/acs.energyfuels.6b03433

[37] C. Zheng, M. Zhu, D. Zhang, Energy Procedia 2015, 75, 847-852. https://doi.org/10.1016/j.egypro.2015.07.176

[38] E. M. Dickinson, Fuel 1980, 59, 290-294. https://doi.org/10.1016/0016-2361(80)90211-2

[39] A. B. Andrews, J. C. Edwards, A. E. Pomerantz, O. C. Mullins, D. Nordlund, K. Norinaga, Energy Fuels 2011, 25,3068-3076. https://doi.org/10.1021/ef2003443

[40] R. Dutta Majumdar, M. Gerken, R. Mikula, P. Hazendonk, Energy Fuels 2013, 27, 6528-6537. https://doi.org/10.1021/ef401412w
[41] B. Avid, S. Sato, T. Takanohashi, I. Saito, Energy Fuels 2004, 18, 1792-1797. https://doi.org/10.1021/ef049960n

[42] R. Evans, Z. Deng, A. K. Rogerson, A. S. McLachlan, J. J. Richards, M. Nilsson, G. A. Morris, Angew. Chem. Int. Ed. 2013, 52, 3199-3202.

https://doi.org/10.1002/anie.201207403

[43] E. Durand, M. Clemancey, A.-A. Quoineaud, J. Verstraete, D. Espinat, J.-M. Lancelin, Energy Fuels 2008, 22, 2604-2610. https://doi.org/10.1021/ef700775z

[44] L. S. C. Junior, S. M. C.de Menezes, H. de Angeli Honorato, M. C. H. de Oliveira, L. C. C. Marques, Energy Fuels 2018, 32, 2793-2800. https://doi.org/10.1021/acs.energyfuels.7b02973

[45] N. V. Lisitza, D. E. Freed, P. N. Sen, Y. Q. Song, Energy Fuels 2009, 23, 1189-1193. https://doi.org/10.1021/ef800631a

[46] H. Kawashima, T. Takanohashi, M. lino, S. Matsukawa, Energy Fuels 2008, 22, 3989-3993. https://doi.org/10.1021/ef800455g

[47] K. Norinaga, V. J. Wargardalam, S. Takasugi, M. lino, S. Matsukawa, Energy Fuels 2001, 15, 1317-1318. https://doi.org/10.1021/ef0100597

[48] J. A. Ostlund, S. I. Andersen, M. Nyden, Fuel 2001, 80, 1529-1533. https://doi.org/10.1016/\$0016-2361(01)00030-8

[49] A. Jerschow, N. Müller. J. Magn. Reson. 1997, 125, 372-375.

https://doi.org/10.1006/jmre.1997.1123

[50] N. V. Lisitza, D. E. Freed, P. N. Sen, Y. Q. Song, Energy Fuels 2009, 23, 1189-1193. https://doi.org/10.1021/ef800631a

[51] L. Tucker, Psychometrika 1966, 31, 279-311. https://doi.org/10.1007/BF02289464

[52] T. Hrenar, moonee, Code for Manipulation and Analysis of Multi- and Univariate Data, rev. 0.6826, 2016.

[53] P. Ungerer, D. Rigby, B. Leblanc, M. Yiannourakou, Mol.Simul. 2014, 40, 115-122. https://doi.org/10.1080/08927022.2013.850499

[54] T. F Headen, E.S. Boek, G. Jackson, T.S. Totton, E.A. Müller, Energy Fuels 2017, 31, 1108-1125. https://doi.org/10.1021/acs.energyfuels.6b02161

[55] J. H Pacheco-Sánchez, I. P. Zaragoza, MartínezMagadán, Pet.Sci. Technol. 2004, 22, 927-942. https://doi.org/10.1081/LFT-120038693

[56] T. Kuznicki, J. H. Masliyah, S. Bhattacharjee, Energy Fuels, 2008, 22, 2379-2389. https://doi.org/10.1021/ef800057n 